\title{
Mission: Impossible? On Empirical-Normative Collaboration in Ethical Reasoning
}

\author{
Sebastian Schleidgen • Michael C. Jungert • \\ Robert H. Bauer
}

Published online: 4 June 2009

(C) Springer Science + Business Media B.V. 2009

\section{Erratum to: Ethic Theory Moral Prac DOI 10.1007/s10677-009-9170-x}

Due to an unfortunate turn of events this article was published online with two errors in the text. In the paragraph under section "2.2.2 Ought Implies Can" starting with the sentence:

"Unlike the intuitive understanding of 'Ought implies Can', the classical philosophical understanding is represented by a material implication between Ought and Can, i.e. $\mathrm{Oa} \rightarrow \mathrm{Ca}$. However, this understanding in our opinion neither is adequate."

The sentence:

"Hence, 'Ought implies Can' has to be adapted to the case at hand, i.e. inserting Oa when $\mathrm{Ca}$ is given in order to fulfil $\mathrm{Oa} \rightarrow \mathrm{Ca}$."

Should read and be regarded by the reader as the final version:

"Hence, Ought implies Can has to be adapted to the case at hand, i.e. inserting $\neg \mathrm{Oa}$ when $\neg \mathrm{Ca}$ is given in order to fulfil $\mathrm{Oa} \rightarrow \mathrm{Ca}$."

The online version of the original article can be found at http://dx.doi.org/10.1007/s10677-009-9170-x.

S. Schleidgen $(\bowtie) \cdot$ M. C. Jungert $\cdot$ R. H. Bauer

Interdepartmental Center for Ethics in the Sciences and Humanities, University of Tuebingen,

Wilhelmstrasse 19, 72074 Tuebingen, Germany

e-mail: sebastian.schleidgen@izew.uni-tuebingen.de 